\title{
RELASI GEREJA DAN NEGARA MENURUT \\ JOHN CALVIN: HUKUMAN MATI ATAS \\ MICHAEL SERVETUS SEBAGAI \\ SEBUAH CONTOH KASUS
}

\author{
Yakub Tri Handoko
}

\begin{abstract}
Abstrak: Pandangan John Calvin tentang relasi antara gereja dan negara merupakan salah satu topik yang sering diperdebatkan. Salah satu contoh kasus yang sering diangkat ke permukaan adalah hukuman mati yang dijatuhkan oleh pemerintah sipil Jenewa atas Michael Servetus, seorang penentang keras doktrin Tritunggal. Sebagian sarjana meyakini bahwa Calvin pantas dituduh bersalah dalam kasus ini karena dia memegang sebuah konsep teologis yang mencampuradukkan gereja dan negara serta karena dia memiliki pengaruh besar di Jenewa.
\end{abstract}

Artikel ini ditulis untuk menawarkan sebuah cara pandang yang berbeda. Dari sisi konsep teologisnya tentang politik (terutama tentang relasi gereja dan negara), Calvin mengakui adanya keterkaitan antara pemerintahan gerejawi dan sipil, tetapi keduanya masih bisa dibedakan dan dipisahkan, walaupun tidak bertentangan. Sayangnya, konsep teologis ini tidak selalu berhasil diterapkan dengan mudah di Jenewa. Kasus Servetus adalah salah satu contoh konkrit dari situasi ini.

Kata-kata kunci: John Calvin, Calvin, Michael Servetus, Servetus, Gereja dan negara, Politik

\begin{abstract}
John Calvin's view about the relationship between church and state is one of the most debated topics. A case often brought up to the surface is the execution of Michael Servetus, a strong opponent of the doctrine of the Trinity, by the civil government of Geneva. Some scholars believe that Calvin deserved the blame in this case because he held a theological concept about
\end{abstract}


the inseparation of church and state, and he also had a massive influence in Geneva.

This article is written to offer a different persepctive. From his theological concept of politics (especially about the relationship between church and state) Calvin acknowledged the interdependence of church and state, but both can still be distinguished and separated, although the two were not contradictory. Unfortunately, this theological concept could not always successfully be applied easily in Geneva. The case of Servetus was one of the concrete examples of the situation.

Keywords: John Calvin, Calvin, Michael Servetus, Servetus, Church and state, Politics

\section{PENDAHULUAN}

Agama dan negara (atau gereja dan negara) merupakan sebuah isu klasik yang terus-menerus mengemuka, terutama di budaya Barat. ${ }^{1}$ Perdebatan yang ada bukan hanya dalam taraf teoritis (konsep) melainkan juga praktis (penerapan). Beragam pandangan dari berbagai tradisi kekristenan sudah diusulkan. ${ }^{2}$ Menyimak ulasan-ulasan yang ada, tidak sukar untuk membenarkan bahwa pencapaian sebuah konsensus tampaknya masih sukar diwujudkan.

\footnotetext{
${ }^{1}$ Baca, misalnya, Noah Feldman, Divided by God: America's Church-State Problem - and What We Should Do About It (New York: Farrar, Straus and Giroux, 2006) dan John Madeley \& Zsolt Enyedi (eds.) Church and State in Contemporary Europe: The Chimera of Neutrality (London: Frank Cass Publishers, 2003).

${ }^{2}$ Paling tidak ada lima pandangan utama: perspektif Katholik, pemisahan klasik, plularis, Anabaptis, dan keadilan sosial. Lihat P. C. Kemeny (ed.), Church, State and Public Justice: Five View (Downers Grove: IVP Academic, 2007).
} 
Artikel ini tentu saja tidak dimaksudkan sebagai sebuah solusi ke arah konsensus. Itu akan menjadi sebuah misi yang mustahil untuk diwujudkan. Apa yang ingin diraih dalam artikel ini hanyalah pendalaman dari salah satu pandangan tentang relasi gereja dan negara dalam tradisi Reformed. Dalam hal ini penulis akan berfokus pada tulisan John Calvin.

Ada beberapa alasan di balik pemilihan fokus ini. Yang terutama tentu saja berkaitan dengan posisi Calvin yang sangat signifikan dalam tradisi dan teologi Reformed. Walaupun Reformed tidak bisa diidentikkan dengan Calvin, ${ }^{3}$ peranan penting Calvin bagi gereja-gereja Reformed-termasuk dalam konsep mereka tentang politik-tampaknya sukar untuk disangkal. ${ }^{4}$

Alasan lain adalah figur Calvin yang kontroversial. Jumlah tulisan yang sangat melimpah dan beragam situasi yang dihadapi membuat pemikiran Calvin terlihat rumit dan membingungkan bagi sebagian orang. Salah satunya adalah tentang konsep politik Calvin. Sebagian ahli mengganggap Calvin terlalu mencampurkan gereja dan negara sedemikian rupa sehingga tidak memberi ruang untuk kebebasan religius bagi mereka yang berseberangan pendapat dengannya. ${ }^{5}$ Skandal Michael Servetus yang dibunuh

\footnotetext{
${ }^{3}$ Lihat Alister E. McGrath, Historical Theology: An Introduction to the History of Christian Thought (Malden: Blackwell, 1998), 161; Carl R. Trueman, "Calvin and Calvinism" dalam The Cambridge Companion to John Calvin, (ed.) Donald K. McKim (Cambridge: Cambridge University Press, 2004), 225.

${ }^{4}$ Misalnya John Witte Jr., The Reformation of Rights: Law, Religion, and Human Rights in Early Modern Calvinism (Cambridge: Cambridge University Press, 2008).

${ }^{5}$ Misalnya Laurence M. Vance, The Other Side of Calvinism (Pensacola: Vance, 1999, edisi revised). Walaupun buku ini tidak secara khusus mengupas pandangan Calvin tentang politik, tetapi Vance tidak lupa menyoroti sikap politik Calvin. Dia meyakini bahwa Calvin terlalu memasukkan agama ke dalam politik sampai mengebiri kebebasan religius. Untuk buku lain yang mengkritisi pandangan Calvin (dan para reformator lain) dari sisi politik, sosial, dan ekonomi, baca Brad S. Gregory, The Unintended Reformation: How a Religious Revolution Secularized Society (Cambridge/London: Harvard University Press, 2012).
} 
gara-gara menolak doktrin Tritunggal adalah salah satu contoh kasus yang sering dipersoalkan. Sebagian ahli yang lain mendeteksi adanya ketegangan dalam pandangan teologis Calvin, yang masih memberi celah bagi resistensi politik jika diperlukan. ${ }^{6}$ Resistensi terhadap pemerintah Jenewa tidak terjadi, karena mereka tergolong pemimpin yang baik, bahkan suportif terhadap gerakan reformasi.

\section{BEBERAPA KENDALA AWAL}

Pembahasan tentang relasi antara gereja dan negara tidak dapat dipisahkan dari konsep Calvin tentang politik. Istilah "politik" merupakan sebuah payung besar yang di bawahnya terdapat begitu banyak aspek yang saling berkaitan. Relasi antara gereja dan negara hanyalah salah satu dari sekian banyak aspek tersebut.

Keterkaitan dengan politik secara luas ini menghadirkan beberapa tantangan. Yang pertama adalah ketidakadaan tulisan Calvin yang secara khusus mengupas tentang politik. William R. Stevenson mengatakan:

"As a theologian and pastor, Calvin addressed political ideas and issues more from necessity that from direct inclination or intention. The proper relationship of the church to civil government inevitably became a major concern for each of the reformers". 7

\footnotetext{
${ }^{6}$ Roland Boer, Political Grace: The Revolutionary Political Theology of John Calvin (Louisville: Westminster John Knox, 2009). Di awal buku ini Boer sempat menilai bahwa penjelasan Calvin kepada Raja Francis I tentang ajaran Reformed yang tidak anti pemerintah sebagai protes yang berlebihan (halaman 120). Calvin masih menyisakan celah untuk pemberontakan terhadap penguasa yang tidak benar (halaman 80-92).

${ }^{7}$ William R. Stevenson, "Calvin and Political Issues," dalam The Cambridge Companion to John Calvin, ed. Donald K. McKim (Cambridge: Cambridge University Press, 2004), 173.
} 
Tidak sukar untuk mengiyakan observasi ini. Salah satu tulisan Calvin yang paling jelas mengupas tentang politik terdapat pada pasal terakhir dari kitab terakhir di Institutes of the Christian Religion. ${ }^{8}$ Hanya satu pasal di antara 20 pasal di kitab terakhir. Pasal itu pun hanya dimunculkan dalam konteks pembahasan tentang gereja.

Ketidakadaan ulasan yang eksplisit ini sebenarnya cukup menarik. Calvin jelas peduli dengan politik. Bahkan dari prakata di bukunya yang monumental yang berjudul Institutio sudah terlihat nuansa politis di dalamnya. Buku ini merupakan sebuah pembelaan terhadap gerakan reformasi (secara khusus dari aliran Reformed) di hadapan Raja Francis I. Calvin ingin menjelaskan bahwa tidak semua aliran dalam gerakan reformasi memiliki sikap ofensif dan resisten terhadap pemerintahan sipil. ${ }^{9}$ Di bagian paling awal dari ulasannya yang spesifik tentang pemerintahan sipil (Inst. IV. 20), Calvin tidak lupa menyinggung tentang dua sikap ekstrim terhadap pemerintahan sipil: menolak pemerintahan sipil atau mencari muka pada pemerintah sipil. Dua ekstrim ini harus disikapi dengan benar, karena "unless we meet both extremes, the purity of the faith will perish" (Inst. IV. 20. 1). Jadi, tujuan politis terlihat cukup kental dalam Institutio.

\footnotetext{
${ }^{8}$ Untuk mempersingkat, bagian selanjutnya dari artikel ini hanya akan menggunakan judul "Institutio".

${ }^{9}$ Di bagian awal buku ini Calvin menulis: "But when I perceive that the fury of certain bad men has risen to such a height in your realm, that there was no place in it for sound doctrine, I thought it might be of service if I were in the same work both to give instruction to my countrymen, and also lay before your Majesty a Confession, from which you may learn what the doctrine is that so inflames the rage of those madmen who are this day, with fire and sword, troubling your kingdom. For I fear not to declare, that what I have here given may be regarded as a summary of the very doctrine which, they vociferate, ought to be punished with confiscation, exile, imprisonment, and flames, as well as exterminated by land and sea" (Preface). Semua terjemahan diambil dari terjemahan Henry Beveridge, Institutes of the Christian Religion (Peabody: Hendrickson, 2008).
} 
Tantangan lain dalam menelusuri konsep Calvin tentang politik berkaitan dengan natur gerakan reformasi yang terbilang unik. Gerakan ini tidak mungkin dipisahkan dari politik atau isu tentang relasi gereja-negara. ${ }^{10}$ Reformasi bukan sekadar gerakan religius yang terpisah dari apa yang terjadi di ranah politik. Dari kacamata Protestan, gerakan ini merupakan reaksi terhadap penyalahgunaan kekuasaan politik oleh pemimpin gereja. Beberapa penganut reformasi bahkan melancarkan upaya-upaya politik tertentu sebagai reaksi terhadap para penguasa, misalnya skandal penempelan poster sampai ke istana raja (The Placards Affair) atau upaya pendirian negara religius oleh golongan Anabaptis yang radikal (Munster Rebellion).

Tantangan terakhir berhubungan dengan situasi kota Jenewa, tempat Calvin memimpin dan mengembangkan gerakan reformasi. Kota yang independen ini sudah merengkuh ide-ide reformasi, bahkan sebelum Calvin tiba di sana. Sesudah Calvin memimpin di sana, terutama pasca kedatangan yang kedua, kota ini menjadi salah satu kota acuan dan perlindungan dalam gerakan reformasi. Pengaruh pemikiran Calvin terhadap kota ini sangat kentara. ${ }^{11}$ Jadi, walaupun Calvin tidak pernah menghasilkan tulisan yang secara khusus mengupas tentang politik, tetapi bukan berarti pengaruhnya dalam dunia politik dapat diremehkan.

Mempertimbangkan semua tantangan di atas, artikel ini akan mengusung beberapa batasan. Dari sisi aspek politik, yang akan lebih banyak disorot adalah relasi antara gereja dan negara, terutama dalam kasus eksekusi Servetus. Dari sisi sumber utama yang digunakan, artikel ini akan berfokus pada buku Institutio,

\footnotetext{
${ }^{10}$ Salah satu buku terbaik tentang hal ini dikarang oleh Carlos M. N. Eire, Reformations: The Early Modern World, 1450-1650 (New Haven \& London: Yale University Press, 2016).

${ }^{11}$ Baca Ronald S. Wallace, Calvin, Geneva, and the Reformation: A Study of Calvin as Social Reformer, Churchman, Pastor, and Theologian (Eugene: Wipf \& Stock, 1998), terutama di halaman 27-130.
} 
terutama tentang "Kebebasan Kristiani" (Inst. III. 19) dan "Pemerintahan Sipil" (Inst. IV. 20). ${ }^{12}$ Dari sisi pokok masalah, pertanyaan yang diangkat adalah: Benarkah Calvin terlalu mencampurkan gereja dan negara (urusan politik) sehingga layak dianggap bersalah dalam hal pengekangan kebebasan religius?

\section{PANDANGAN CALVIN TENTANG GEREJA DAN NEGARA}

Untuk memahami pandangan teologis Calvin secara tepat, terutama dalam kasus hukuman mati atas Servetus, ada dua aspek yang tidak boleh diabaikan. Yang pertama adalah teologi politiknya. Yang kedua adalah politik praktisnya. Walaupun dua hal ini dalam banyak hal berkaitan dan selaras, tetapi tidak selalu demikian. Menyoroti Calvin hanya dari salah satu aspek merupakan ketidakadilan terhadap dia.

\section{TEOLOGI POLITIK CALVIN}

Seperti sudah disinggung sebelumnya, gereja dan negara tidak terpisahkan dari konsep teologi Calvin. Pembahasan tentang pemerintahan sipil di Institutio bahkan muncul dalam konteks pembahasan tentang gereja. Secara umum semua orang akan setuju bahwa reformasi gereja mencakup aspek-aspek politis. Pendeknya, ada pembenaran yang solid untuk menghubungkan Calvin dan politik (secara khusus tentang relasi gereja dan negara).

Walaupun demikian, penjelasan di atas tidak berarti bahwa pemerintahan gerejawi dan sipil tidak bisa dan tidak perlu dibedakan. Pembedaan ini sudah terlihat dari istilah-istilah yang

\footnotetext{
${ }^{12}$ Sumber-sumber lain yang juga bermanfaat berasal dari tafsiran Calvin (terutama Ulangan, Yeremia, dan Roma), surat-surat, dan traktat-traktatnya. Baca misalnya Henry Beveridge \& Jules Bonnet, Selected Works of John Calvin: Tracts and Letters (Grand Rapids: Baker: 1983).
} 
Calvin kenakan untuk pemerintahan gerejawi dan sipil. Dia menulis (Inst. III. 15):

Therefore, lest this prove a stumbling-block to any, let us observe that in man government is twofold: the one spiritual, by which the conscience is trained to piety and divine worship; the other civil, by which the individual is instructed in those duties which, as men and citizens, we are bold to perform. To these two forms are commonly given the not inappropriate names of spiritual and temporal jurisdiction, intimating that the former species has reference to the life of the soul, while the latter relates to matters of present life, not only to food and clothing, but to the enacting of laws which require a man to live among his fellows purely honorably, and modestly. The former has its seat within the soul, the latter only regulates the external conduct. We may call the one the spiritual, the other the civil kingdom.

Maksud dari pembedaan ini tentu saja bukan untuk mengontraskan atau memisahkan keduanya secara kaku. Calvin berpendapat:

"But as we lately taught that that kind of government is distinct from the spiritual and internal kingdom of Christ, so we ought to know that they are not adverse to each other" (Inst. IV. 20. 2).

Tidak ada kontradiksi antara memberikan tugas untuk menegakkan agama pada pemerintahan sipil dengan menyatakan kebebasan iman dan ibadah Kristen dari pemerintahan sipil (Inst. IV. 20. 3). Yang spiritual membawa kebaikan internal dan kekal, yang sipil membawa kebaikan eksternal dan temporal. Keduanya sama-sama diperlukan. ${ }^{13}$

\footnotetext{
${ }^{13}$ Calvin juga mengajarkan tentang tujuan pemerintahan sipil. Sebagian dari tujuan ini sangat berkaitan dengan hal-hal spiritual atau orang-orang Kristen. Tujuan tersebut mencakup: (i) melindungi ibadah eksternal kepada Allah; (ii) membela ajaran kesalehan yang benar dan posisi gereja; (iii) menyesuaikan
} 
Melalui pembedaan yang ada, keteraturan dan ketertiban dapat diterapkan pada semua orang sesuai dengan domain masingmasing. Mereka yang non-Kristen berada di bawah aturan sipil. Mereka yang Kristen berada di bawah aturan gereja sekaligus sipil. Dengan kata lain, ada dua jalur moralitas yang diberlakukan, seperti yang diungkapkan oleh John Witte:

These norms, in turn, give rise to two tracks of morality: a simple morality of duty demanded of all persons, regardless of their faith, and a higher morality of aspiration demanded of believers in order to reflect their faith. In Calvin's mind, commandments and counsels, musts and shoulds, absolutes and adiaphora can thereby be distinguished. This two-track system of morality corresponded roughly to the proper division of jurisdiction between church and state, as Calvin saw it. It was the church's responsibility to teach aspirational spiritual norms. It was the state's responsibility to enforce mandatory civil norms. ${ }^{14}$

Sehubungan dengan aturan-aturan di ranah sipil, Calvin terlihat tidak memiliki agenda untuk mendirikan sebuah negara Kristen dengan aturan-aturan Kristiani yang mengikat semua orang tanpa terkecuali. Menurut dia, landasan pemerintahan sipil bukan hukum-hukum legal di Perjanjian Lama (Inst. IV. 20. 14-15). Hukum yang diberlakukan seharusnya lebih bersumber dari hukum moral dan hati nurani (Inst. IV. 20. 16). Sifat dari hukum-hukum tersebut adalah universal. ${ }^{15}$ Matthew Tuininga secara tepat mengungkapkan hal ini:

"It led him to conceive of politics not as a means of transforming society into the kingdom of God according to

\footnotetext{
kehidupan orang percaya dengan komunitas; (iv) membentuk perilaku sosial yang sesuai dengan kebenaran sipil; (v) mendamaikan satu dengan yang lain; (vi) menciptakan kedamaian dan ketenangan (Inst. IV. 20. 2).

${ }^{14}$ Witte, The Reformation of Right, 78.

${ }^{15}$ William J. Bouwsma, John Calvin: The Sixteenth-Century Portrait (New York/Oxford: Oxford University Press, 1988), 206.
} 
the dictates of Christian scriptures, but as an endeavor to secure temporal order and civil rigtheousness in accord with reason, natural law, and the virtues of charity and prudence". 16

Konsep yang sekilas terlihat sangat humanis ini sebenarnya tetap dilandaskan pada firman Tuhan. Calvin memiliki pandangan yang positif terhadap penetapan ilahi dan keniscayaan pemerintah sipil. Pemerintahan sipil ditetapkan oleh Allah sendiri (Inst. IV. 20. 1, 23, 30). Pemerintahan sipil sangat diperlukan seperti manusia membutuhkan roti, air, matahari, dan udara (Inst. IV. 20. 3) untuk mengekang manifestasi dosa (Comm. Romans 13:3, "to provide for the tranquility of the good and to restrain the waywardness of the wicked").

Berangkat dari konsep teologis di atas, ketaatan kepada pemerintahan sipil bukanlah sebuah pilihan bagi orang Kristen. Kewajiban mereka bukan sekadar memberi ruang bagi toleransi, tetapi penghargaan, yang dibangun di atas kasih kepada Allah (Inst. IV. 20. 22). Salah satu contoh ketaatan adalah, misalnya, menghindarkan diri dari tindakan-tindakan politik publik yang tidak dilegitimasi oleh pemerintah (Inst. IV. 20. 23). Bagi Calvin, ketaatan bahkan tetap perlu ditujukan pada pemerintah yang tidak baik (Inst. IV. 24-29). Perkecualian diberlakukan pada perintah pemerintah yang bertabrakan dengan firman Tuhan (Inst. IV. 20. 32). ${ }^{17}$

\section{POLITIK PRAKTIS CALVIN}

Apa yang dipikirkan oleh Calvin tidak selalu berhasil diterapkan dalam pemerintahan sipil di Jenewa. Walaupun dia sudah berusaha untuk menentukan batasan yang jelas tentang tugas

\footnotetext{
${ }^{16}$ Matthew Tuininga, Calvin's Political Theology and the Public Engagement of the Church (Cambridge: Cambridge University Press, 2017), 1.

${ }^{17}$ Seberapa jauh Calvin memberi ruang bagi perlawanan terhadap pemerintahan sipil merupakan topik yang banyak menyedot perhatian dan perdebatan. Isu yang rumit ini membutuhkan ulasan tersendiri, yang tidak bisa diberikan di sini.
} 
masing-masing pejabat gerejawi (Inst. IV. 3) maupun antara pejabat gerejawi dan sipil (Inst. IV. 20. 1-2), perjuangan untuk mengimplementasikan pembedaan tersebut membutuhkan proses yang sukar dan panjang.

Kesulitan ini sedikit banyak bersumber dari situasi Jenewa. Semua pejabat sipil adalah anggota gereja. Dalam banyak hal mereka mengikuti pandangan Calvin. Namun, sikap ini tidak selalu mereka tunjukkan. Banyak pemikiran politis Calvin yang ditolak oleh pemerintah Jenewa, entah karena dianggap intervensi terhadap domain kekuasaan mereka atau sebagai manuver politik tertentu. ${ }^{18}$ Dia pun tidak jarang mendapatkan perlawanan dari pihak-pihak tertentu, sehingga dia beberapa kali berniat untuk secara serius mengundurkan diri dari jabatannya di Jenewa. ${ }^{19}$

Sebagai contoh adalah tentang disiplin atau hukuman atas pelanggaran. Walaupun Calvin sudah memaparkan pandangannya yang cukup komprehensif dan jelas tentang disiplin gereja (Inst. IV. 12. 1-13), tidak semua poin tersebut diterima dan diterapkan. Sejauh mana pejabat gerejawi dan sipil berwenang untuk menjatuhkan hukuman atas sebuah kesalahan? Kesalahan apa saja yang termasuk dalam wilayah Consistoire ${ }^{20}$ dan sipil? Bagaimana seandainya disiplin yang diambil oleh gereja membahayakan kepentingan sipil? Bagaimana seandainya terjadi sebaliknya?

Penjelasan di atas membawa pada sebuah poin penting: Kontribusi Calvin dalam politik Jenewa sebenarnya lebih terletak pada teologi politis, bukan politik praktis. Calvin bahkan tidak

\footnotetext{
${ }^{18}$ Francois Wendel, Calvin: Origins and Development of His Religious Thought (terj. Philip Mairet, Durham: The Labyrinth, 1963), 70-71.

19 Sebagai contoh, dia mendapat tantangan yang serius dan bertubi-tubi kelompok Libertines dan lainnya. Baca T. H. L. Parker, John Calvin (Tring/Batavia/Sydney: A Lion Paperback, 1975), 127-137.

20 Istilah ini merujuk pada semacam sinode atau dewan disiplin gereja. Anggotanya terdiri dari para pendeta dan penatua terpilih. Tugas mereka adalah mengintegrasikan antara kehidupan sipil dan gereja.
} 
sepenuhnya berhasil meletakkan gereja sebagai institusi yang independen dari pemerintah sipil, sebagaimana diungkapkan oleh Wendel:

"And in fact, even in the days when Calvin's personal authority was no longer questioned, he never succeeded in withdrawing the Genevan Church from the control of the Magistracy". 21

Tindakan dan komitmen politiknya bersifat sangat situasional: usaha terbaik Calvin untuk menginterpretasikan implikasi praktis dari hukum-hukum alamiah pada tempat dan waktu itu, yang didasarkan pada hukum bangsa-bangsa, akal budi, dan filsafat politik non-Kristiani. ${ }^{22}$

Di tengah situasi seperti inilah kasus Servetus sebaiknya diletakkan untuk dikaji ulang. Andil Calvin dalam kasus eksekusi sebenarnya sangat minimal. ${ }^{23}$ Dia hanya berperan sebagai penasihat teknis atau saksi ahli, bukan prosekutor ${ }^{24}$ Akseptabilitas Calvin di mata pejabat sipil pada saat momen ini terjadi bahkan bisa dibilang sangat rendah. Memulai uraiannya tentang kasus Servetus, Parker berkata: "It was at this point, when Calvin's authority in Geneva was at its lowest, when he was in fact defeated, that there happened an event of such magnitude and with such implications that the whole face of the battle was changed". 25 Pendeknya, walaupun Calvin tidak bisa dibilang sama sekali tidak terkait dalam eksekusi Servetus, tetapi dia tidak sejelek yang dipikirkan sebagian orang. ${ }^{26}$

\footnotetext{
${ }^{21}$ Wendel, Calvin, 53.

22 Tuininga, Calvin's Political Theology, 3-4.

${ }^{23}$ Bruce Gordon, Calvin (Yale University Press, 2009), 219.

${ }^{24}$ Alister McGrath, A Life of John Calvin (Malden: Blackwell, 1990), 111-120.

${ }^{25}$ Parker, John Calvin, 138.

${ }^{26}$ Salah satu pembelaan singkat yang baik dan cukup objektif tentang isu ini ditulis oleh Mark. R. Talbot, "A Note on Calvin and Servetus" dalam With Calvin in the Theater of God: The Glory of Christ and Everyday Life, (eds.) John Piper \& David Mathis (Wheaton: Crossway, 2010), 147-152.
} 
Seandainya semua keputusan diserahkan ke dalam tangan Calvin, dia sangat mungkin tidak akan menjatuhkan hukuman mati pada Servetus. Dalam konsep Calvin tentang disiplin gereja, pelanggaran publik terberat pun hanya dikenai hukuman berupa pengucilan (excommunication) selama durasi tertentu (Inst. IV. 12. 6). Dia bahkan mengecam beberapa bentuk disiplin pada zaman sebelumnya yang dia anggap terlalu keras (Inst. IV. 12. 8-9, 11).

Dalam kasus Servetus, dia sudah melakukan yang terbaik yang dia bisa. ${ }^{27}$ Upaya bertemu secara langsung sudah pernah coba dilakukan. Dia melayani korespondensi dengan Servetus. Peringatan-peringatan keras, baik secara teologis dan politis, sudah diberitahukan kepada Servetus. Tatkala vonis hukuman mati sudah dijatuhkan, dia masih memohon agar bentuk hukuman yang diberikan adalah pemancungan, bukan pembakaran hidup-hidup. Upaya ini pun ditolak oleh pejabat sipil Jenewa.

\section{KESIMPULAN}

Pendapat yang mengatakan bahwa Calvin mencampuradukkan urusan gereja dan negara sedemikian rupa sehingga dia memberangus kebebasan religius merupakan tuduhan yang tidak adil. Pendapat ini hanya didasarkan pada satu sisi saja, yaitu politik praktis Calvin, padahal teologi politis Calvin seringkali tidak selaras dengan politik praktisnya. Bukan karena dia tidak konsisten. Semua karena wewenangnya yang terbatas di Jenewa.

Dalam kasus hukuman mati yang dijatuhkan oleh pejabat sipil kepada Servetus, Calvin mungkin sudah melakukan apa yang berada dalam wilayah wewenangnya. Walaupun dia memang sangat menentang ajaran Servetus dan menganggap Servetus

${ }^{27}$ Lihat Parker, John Calvin, 138-146. 
sebagai pribadi yang buruk, keputusan untuk menghukum mati bukan berasal dari dia.

\section{DAFTAR RUJUKAN}

Beveridge, Henry \& Bonnet, Jules. Selected Works of John Calvin: Tracts and Letters. Grand Rapids: Baker: 1983.

Beveridge, Henry. Institutes of the Christian Religion. Peabody: Hendrickson, 2008.

Boer, Roland. Political Grace: The Revolutionary Political Theology of John Calvin. Louisville: Westminster John Knox, 2009.

Bouwsma, William J. John Calvin: The Sixteenth-Century Portrait. New York/Oxford: Oxford University Press, 1988.

Eire, Carlos M. N. Reformations: The Early Modern World, 14501650. New Haven \& London: Yale University Press, 2016.

Feldman, Noah. Divided by God: America's Church-State Problem - and What We Should Do About It. New York: Farrar, Straus and Giroux, 2006.

Gordon, Bruce. Calvin. Yale University Press, 2009.

Gregory, Brad S. The Unintended Reformation: How a Religious Revolution Secularized Society. Cambridge/London: Harvard University Press, 2012.

Kemeny, P. C. (ed.), Church, State and Public Justice: Five View. Downers Grove: IVP Academic, 2007. 
Madeley, John \& Enyedi, Zsolt (eds.). Church and State in Contemporary Europe: The Chimera of Neutrality. London: Frank Cass Publishers, 2003.

McGrath, Alister E. Historical Theology: An Introduction to the History of Christian Thought. Malden: Blackwell, 1998.

McGrath, Alister. A Life of John Calvin. Malden: Blackwell, 1990.

Parker, T. H. L. John Calvin. Tring/Batavia/Sydney: A Lion Paperback, 1975.

Stevenson, William R. "Calvin and Political Issues," dalam The Cambridge Companion to John Calvin, (ed.) Donald K. McKim. Cambridge: Cambridge University Press, 2004.

Talbot, Mark. R. "A Note on Calvin and Servetus" dalam With Calvin in the Theater of God: The Glory of Christ and Everyday Life, (eds.) John Piper \& David Mathis. Wheaton: Crossway, 2010.

Trueman, Carl R. "Calvin and Calvinism" dalam The Cambridge Companion to John Calvin, (ed.) Donald K. McKim. Cambridge: Cambridge University Press, 2004.

Tuininga, Matthew. Calvin's Political Theology and the Public Engagement of the Church. Cambridge: Cambridge University Press, 2017.

Vance, Laurence M. The Other Side of Calvinism. Pensacola: Vance, 1999, edisi revised. 
Wallace, Ronald S. Calvin, Geneva, and the Reformation: A Study of Calvin as Social Reformer, Churchman, Pastor, and Theologian. Eugene: Wipf \& Stock, 1998.

Wendel, Francois. Calvin: Origins and Development of His Religious Thought (terj. Philip Mairet). Durham: The Labyrinth, 1963.

Witte, John Jr. The Reformation of Rights: Law, Religion, and Human Rights in Early Modern Calvinism. Cambridge: Cambridge University Press, 2008. 